\title{
Alcohol consumption and corresponding factors: A novel perspective on the risk factors of esophageal cancer (Review)
}

\author{
QIAO PENG ${ }^{1}$, HUI CHEN ${ }^{2}$ and JI-RONG HUO ${ }^{1}$ \\ ${ }^{1}$ Department of Gastroenterology, The Second Xiangya Hospital of Central South University, Changsha, Hunan 410011; \\ ${ }^{2}$ Department of Gastroenterology, People's Hospital of Taizhou, Taizhou, Jiangsu 225300, P.R. China
}

Received February 4, 2015; Accepted February 25, 2016

DOI: 10.3892/ol.2016.4401

\begin{abstract}
Esophageal cancer is the eighth most common type of cancer in the world, and the sixth most common cause of mortality from cancer. Alcohol consumption is the major risk factor for esophageal cancer, due to the worldwide prevalence and high carcinogenicity of the ethanol metabolite. In epidemiological studies, the efficiency of alcohol intake to enhance the risk of esophageal cancer is altered by daily ethanol consumption, type of alcoholic beverages ingested, time since quitting drinking, age of drinking initiation, differences in population and subtypes of esophageal cancer. Corresponding factors, including gene polymorphisms, tobacco smoking, oral microorganisms and folate deficiency, reveal a synergistic effect in concurrent alcohol users that may lead to an increased risk of developing esophageal cancer. Consequently, esophageal cancer prevention involves multiple aspects, including quitting drinking and smoking, maintaining an adequate oral health and ingesting adequate quantities of folate, particularly in genetically high-risk populations.
\end{abstract}

\section{Contents}

1. Introduction

2. Association between alcohol consumption and the risk of esophageal cancer

3. Interactions between alcohol consumption and the corresponding factors

4. Conclusion

Correspondence to: Professor Ji-Rong Huo, Department of Gastroenterology, The Second Xiangya Hospital of Central South University, 139 Renminzhong Road, Changsha, Hunan 410011, P.R. China

E-mail: huojirong2014@outlook.com

Key words: esophageal cancer, risk factors, alcohol, epidemiology, corresponding factors

\section{Introduction}

Esophageal cancer is the eighth most common type of cancer in the world and the sixth most common cause of mortality from cancer, according to the results of the GLOBOCAN project, published by the International Agency for Research on Cancer in 2012 (1). Alcohol consumption has been demonstrated to be a major risk factor for developing esophageal cancer, particularly esophageal squamous cell carcinoma (ESCC) in men (2-4). Globally, prevailing alcohol intake has been an increasingly dire health problem due to the carcinogenicity of ethanol $(5,6)$. Chronic ethanol ingestion leads to nutritional deficiencies and generation of reactive oxygen species (ROS). In addition, ethanol acts as a solvent of carcinogens (7). Acetaldehyde, the primary metabolite of ethanol, is highly mutagenic, due to its ability to form exocyclic DNA adducts (8). The diversity of carcinogenetic mechanisms may reflect the wide interaction between ethanol and cofactors from the inner and outer environment (9). The present study focuses on how alcohol consumption associates with the risk of esophageal cancer and interacts with corresponding factors, mainly from an epidemiological aspect.

\section{Association between alcohol consumption and the risk of esophageal cancer}

Daily ethanol consumption. The risk of developing esophageal cancer has been indicated to increase with an increase in alcohol intake (10-18). Fan et al (18) demonstrated a positive association between the total amount of ethanol intake during lifetime and the risk of esophageal cancer. In another study, heavy ethanol intake (>53.3 g/day) was significantly associated with the risk of esophageal cancer, even in a relatively short duration ( $\leq 20$ years) (12). Castellsagué et al (19) demonstrated that, compared with individuals with a decreased daily alcohol consumption for numerous years, those drinking large amounts of alcohol for a shorter period of time tend to carry an increased risk of developing esophageal cancer. Therefore, compared with a long duration of alcohol consumption, an increased daily amount of alcohol consumption may be a more effective risk factor of esophageal cancer.

Type of alcoholic beverages. As the major component of alcoholic beverages, ethanol is the determinant of the risk of 
esophageal cancer (20). Acetaldehyde, though present in trace amounts in beverages, may be another risk factor, due to its strong carcinogenicity (21). The most prevalent beverage in a region tends to have the greatest relative risk (22). Baijiu (a type of hard liquor with a high alcohol content) in China, wine in Italy, calvados in France and spirits in South America enhance the development of esophageal cancer, due to their high ethanol content and great popularity in each particular region $(12,19,22,23)$. In contrast, wine consumption was observed to reduce the risk of esophageal cancer in a previous cohort study (17). Despite the regional variations in drinking habits, certain antitumor substances, including flavonoids, that are contained in wine may explain the inconsistencies reported across different studies (24). In previous studies, beer had a relatively mild effect on the risk of esophageal cancer, even with large consumption, compared with other beverages, due to its low ethanol content $(17-19,22)$.

Years since quitting drinking. There are controversies regarding the association between the time since quitting drinking and the risk of developing esophageal cancer. Castellsagué et al (19) and Wu et al (25) demonstrated a virtually negative association in men. The conclusions of the study by Zambon et al (14) were more complex. Compared with persistent drinkers, drinking cessation was associated with certain increased risk in the first 10 subsequent years and with a non-significant risk reduction thereafter (14). These differences may be due to variations in reference and population stratification in case-control studies.

Age of drinking initiation. This variant has an uncertain effect on the risk of esophageal cancer. In the study by Castellsagué et al (19), along with increasing daily alcohol intake, there was a greater tendency for individuals that started drinking at an older age to develop esophageal cancer. However, Zambon et al (14) showed no association between the age of drinking initiation and the risk of developing esophageal cancer.

Differences in population. Different populations involved in various studies affect the strength of the association between alcohol and esophageal cancer. Alcohol consumption may be a great risk factor for esophageal cancer in Caucasian populations $(14,19,26)$; however, the effect of alcohol consumption on the risk of developing esophageal cancer appears to be much weaker in Asian populations $(25,27)$, particularly in certain regions with high incidence of esophageal cancer, including Linxian (China), where alcohol consumption is not a major risk factor for esophageal cancer (28). This weak association may be attributed to strong confounding factors, including gene polymorphism and other carcinogens that dilute the effect of alcohol $(11,28)$. In studies concerning gender, the association between alcohol consumption on the risk of developing esophageal cancer was weaker in women compared with men, which may be partly explained by a short history of alcohol exposure and low alcohol prevalence among women $(19,25)$.

Subtypes of esophageal cancer. A large number of studies have indicated a strong positive association between alcohol intake and ESCC $(11,12,15,17,18,29)$. However, the association between alcohol intake and esophageal adenocarcinoma (EAC) is attenuated. The two cohort studies by Steevens et al $(17,30)$ revealed that alcohol consumption did not promote the risk of developing EAC or Barrett's esophagus (precancerous lesions of EAC). Other analyses reached similar conclusions $(29,31,32)$. The study by Akiyama et al (33) showed a moderate increase in the risk of Barrett's esophagus in Japanese male drinkers. In the meta-analysis conducted by Lubin et al (15), odd ratios (ORs) with drinking-years exhibited an inverse association with alcohol consumption in $<5$ drinks/day consumers, and no association in heavier consumers. The distinct outcome of EAC and ESCC may be explained by the different pathogenesis of these two subtypes of esophageal cancer (34).

\section{Interactions between alcohol consumption and the corresponding factors}

Gene polymorphism. Since numerous genes participate in the catabolism of ethanol directly or indirectly, gene polymorphism greatly affects the carcinogenicity of ethanol in various populations (35). In several epidemiological studies, even genes that are barely associated with ethanol metabolism revealed similar effects (Table I).

Alcohol dehydrogenases (ADH) and aldehyde dehydrogenases $(\mathrm{ALDH})$ are the major enzymes that participate in the metabolism of ethanol. Ethanol is oxidated to acetaldehyde by $\mathrm{ADH}$, and the subsequent oxidation of acetaldehyde to acetate is catalyzed by ALDH. Polymorphism of these gene families caused by point mutations alters enzymatic activity, resulting in potential individual variations in acetaldehyde exposure (36-38).

The ADH1B*2 (Arg48His) allele encodes a more active subunit of ADH1B, compared with the ADH1B*1 allele, the homodimer of which has a $\sim 40$-fold greater maximum velocity than the ADH1B*1/2*1 form of ADH1B $(39,40)$. The enzyme encoded by the ADH1C*1 (Ile350Val) allele has a 2.5-times faster speed of acetaldehyde production than the enzyme encoded by the ADH1C*2 allele $(39,40)$. ADH1B*1 has been previously demonstrated to enhance the risk of esophageal cancer in Asian populations (41-45). By contrast, the association between ADH1C and the risk of esophageal cancer is contradictory. Yokoyama et al (41) and Muto et al (46) demonstrated that $\mathrm{ADH} 1 \mathrm{C}^{*} 2$ increased the risk of developing esophageal cancer; however, the study by $\mathrm{Wu}$ et al (45) showed no enhanced risk. Furthermore, ADH1C*1, but not $\mathrm{ADH} 1 \mathrm{C} * 2$, enhanced the risk of esophageal cancer in certain studies conducted in western countries $(47,48)$. This contradiction may be explained by different linkage disequilibrium patterns among various populations $(40,48)$. ADH7 is mainly expressed in the upper gastrointestinal tract (49), and certain studies showed that single nucleotide polymorphisms of ADH7 were associated with esophageal cancer in alcohol drinkers (50-52).

The ALDH2*2 (Glu487Lys) allele, which encodes an inactive subunit of ALDH, occurs most frequently in Asian countries, including China, Japan, Korea, Mongolia and Indochina (53). As the major enzyme affecting blood acetaldehyde concentration, the ALDH $2 * 1 * 2$ and ALDH2*2*2 forms of ALDH produced a 6- and 19-fold increased acetaldehyde concentrations, respectively, compared with the ALDH2*1*1 
form (54). The enhancing effect of the ALDH2*2 allele on the risk of ESCC in Japanese men was demonstrated in previous reports by Yokoyama et al $(55,56)$. A previous meta-analysis including seven case-control studies in Asia revealed a positive association between the risk of developing esophageal cancer and the level of alcohol consumption in subjects carrying the ALDH2*1*2 genotype (57). The ALDH2*2 and ADH1B*1 alleles acted in a multiplicative manner to enhance the risk of esophageal cancer $(41,42)$. Notably, although the ALDH2*1*2 genotype increased the risk of developing esophageal cancer, the ALDH $2 * 2 * 2$ genotype reduced the risk in a previous study (42). It may be hypothesized that increased blood levels of acetaldehyde due to the ALDH2*2 homodimer results in the 'alcohol flushing response', which includes facial flushing, nausea and tachycardia, preventing people from heavy drinking, thus decreasing the possibility of esophageal cancer $(58,59)$. Individuals that possessed the ALDH $2 * 1 / 2 * 2$ genotype and also carried ADH2*1/2*1 did not exhibit flushing following drinking. These individuals tended to be heavy drinkers and had the greatest risk of developing esophageal cancer (58).

Cytochrome P450 2E1 (CYP2E1) is the major enzyme in the microsomal ethanol oxidation system (60). Induced by ethanol consumption, CYP2E1 metabolically activates procarcinogens and produces noxious ROS during ethanol oxidation (61). Compared with CYP2E1*c1 (Pst I-/Rsa I+), the mutant CYP2E1*c2 (Pst I+/Rsa I-) is considered to display a decreased activity (38). Individuals with the CYP2E1*c1*c1 genotype possessed a much greater risk of developing ESCC compared with those carrying the CYP2E1*c2 allele among Chinese drinkers; Furthermore, CYP2E1*c1*c1 exhibits a synergistic interaction with ALDH2*1*2 and methylenetetrahydrofolate reductase (MTHFR)677 (C/T+T/T) $(62,63)$. However, in several cases, particularly in Caucasians, gene polymorphisms of CYP2E1 have no association with esophageal cancer (64-67).

Polymorphisms of the enzymes involved in the folate metabolic pathways also impact the development of esophageal cancer. MTHFR, a key enzyme in folate metabolism, is important for DNA methylation $(68,69)$. Altered activity of MTHFR may cause DNA hypomethylation, a process associated with carcinogenesis (70,71). The most commonly studied MTHFR mutant is the change from $\mathrm{C}$ to $\mathrm{T}$ at nucleotide 677 of the MTHFR gene, which results in an alanine to valine substitution in the MTHFR enzyme (72). The homozygote and heterozygote of $667 \mathrm{~T}$ exhibit a 30 and $65 \%$ activity, respectively, compared with the $100 \%$ activity exhibited by the 677CC genotype (73). Previous case-control studies and meta-analyses have revealed that the MTHFR C677T allele increased the risk of developing ESCC (74-78). In coordination with ADLH2*2, individuals with C677T demonstrated elevated ORs (74). The MTHFR 677T allele collaborated with alcohol consumption to increase the risk of esophageal cancer in former, moderate and heavy drinkers (75). However, the interaction between MTHFR 677T and alcohol intake is not consistent in certain meta-analyses $(77,78)$. A previous study conducted in Japan reached the opposite conclusion, and reported that the MTHFR 677TT genotype significantly decreased esophageal cancer risk in heavy drinkers (79). This inconsistency may be due to the regional variations in folate consumption among different populations, which would suggest a significant gene-nutrient interaction between folate consumption and MTHFR genotype (78-80).

Certain gene polymorphisms with little association with the metabolism of alcohol somewhat alter the risk of esophageal cancer. According to the review by Hiyama et al (81), carcinogen metabolism-associated genes [such as cytochrome P450 family 1 subfamily A member 1 (CYP1A1), glutathione S-transferases (GSTs) and natural antisense transcripts], DNA repair genes (such as X-ray repair complementing defective repair in Chinese hamster cells 1 and xeroderma pigmentosum group D), cell cycle control genes (such as tumor protein p53 and cyclin D1) and oncogenes (such as v-myc avian myelocytomatosis viral oncogene lung carcinoma derived homolog) showed varying degrees of association with esophageal cancer. However, inconsistencies exist in various studies, and certain studies showed that the aforementioned genes interacted with alcohol consumption in the development of esophageal cancer. The GSTM1 deletion, GSTP1 341C/T+341T/T and CYP1A1 Val/Val genotypes were indicated to possess much greater ORs in alcohol drinkers compared with non-drinkers in two case-control studies $(82,83)$.

Tobacco smoking. Similarly to alcohol beverages, tobacco has spread all over the world, with $>1$ billion current smokers (84). The majority of alcohol drinkers are also tobacco smokers (85). Epidemiological studies involving the combined effects of tobacco and alcohol have consistently revealed the existence of a positive synergistic effect between these two factors on the risk of developing esophageal cancer (14,17-19,25,86-88) (Fig. 1). The two variants usually exhibit a mutual dose-response association $(14,17,19)$, and a combined OR reached a value of 130 in an Italian study (14). However, the effect of this combination appeared to be much weaker in Asian populations, with a combined OR of $<10$ at the highest alcohol and tobacco use $(18,25)$. Similarly, women had a less combined OR compared with men $(19,25)$. The variation between populations may be attributed to regional and gender differences in terms of tobacco prevalence $(25,89)$. Reportedly, $\sim 66.9 \%$ of men but only $4.2 \%$ of women are tobacco smokers in China, whereas the prevalence of smoking among men and women was estimated to be 35 and $22 \%$, respectively, in developed countries, and 50 and 9\%, respectively, in developing countries $(25,89)$.

Tobacco smoke contains $>60$ carcinogens, including tobacco-specific nitrosamines such as 4-(methylnitrosamino) -1-(3-pyridyl)-1-butanone and N'-nitrosonornicotine, and polycyclic aromatic hydrocarbons (PAHs) such as benzo[a]pyrene and acetaldehyde $(84,90,91)$. Tobacco smoke interacts with ethanol in the initiation of cancer in several ways: i) Ethanol activates the CYP members that metabolize tobacco procarcinogens to carcinogens (91); ii) ethanol increases cellular membrane permeability and acts as a solvent to facilitate the penetration of molecules like PAHs into the intracellular domain of mucosal epithelial cells (91); and iii) tobacco smoke, as a direct source of acetaldehyde or as a regulator of the population of oral bacteria, cooperatively elevates acetaldehyde exposure in a direct or indirect way by 7-fold, compared with alcohol drinking alone (92). 
Oral microorganisms. Epidemiological evidence of the associations between salivary acetaldehyde and esophageal cancer remains limited, but several experiments conducted in animals may aid to elucidate the local carcinogenic effects of acetaldehyde on the mucosa of the upper digestive tract. Previous studies suggested that long-term alcohol consumption may induce increased cell proliferation in the oral and esophageal mucosa of rats $(93,94)$. As a more direct model for reflecting the effect of salivary acetaldehyde, rats that drank water with an increased concentration of acetaldehyde showed hyperplasia and hyperproliferation in the epithelia of their upper gastrointestinal tract (95).

Oral microbes and prolonged ethanol use are two major factors in the generation of salivary acetaldehyde. This hypothesis has been previously demonstrated in vivo by Homann et al (96). In this study, moderate ethanol ingestion resulted in carcinogenic amounts of acetaldehyde in the saliva; whereas using an antiseptic mouthwash with chlorhexidine prior to ethanol exposure, in vivo acetaldehyde production decreased by $>50 \%$, with a parallel evident decrease in bacterial counts. Yokoyama et al (97) showed that following 3 weeks of abstinence, the microorganism count and salivary acetaldehyde production decreased in alcoholics. These results indicate a certain mutual effect between ethanol and oral microorganisms. Chronic alcohol consumption may increase bacterial concentrations through affecting salivary gland morphology and decreasing salivary flow $(98,99)$.

As another promoter of microbial acetaldehyde production, tobacco smoking may exhibit a strong association with increased salivary acetaldehyde during alcohol drinking. Smokers that smoke while drinking have 7-fold increased salivary acetaldehyde levels compared with non-smokers (100). With the exception of the direct contribution of acetaldehyde by tobacco smoke, the alteration of oral microorganisms by smoking is also a major source of the increased concentration of salivary acetaldehyde (99). As previously reported, increased yeast infections and conversions from Gram-negative to Gram-positive bacteria has been demonstrated in smokers $(99,101,102)$. However, oral bacteria may activate the nitrosamines from tobacco smoking to carcinogenic adducts by forming hydroxylated products (103-105).

Although $>700$ bacterial species inhabit the oral cavity (105), only the prevalence of several aerobic Gram-positive bacteria and yeast have been proved to play a leading role in acetaldehyde production (106). This phenomenon may due to the increased ADH activity, which has been confirmed in Streptococcus gordonii V2016 (107), Neisseria (108) and Streptococcus salivarius (109), the prevalence of aerobic Gram-positive bacteria and yeast are important in acetaldehyde production (109), due to their increased ADH activity. Other species, including hemolytic Streptococcus viridans var., Stomatococcus sp. and Corynebacterium sp., are not highly efficient in producing acetaldehyde; however, these species were significantly associated with increased acetaldehyde levels in saliva (110). Yeasts such as Candida albicans were indicated to have great capacity to produce carcinogenic acetaldehyde (111).

Folate deficiency. In previous studies, people ingesting a greater quantity and variety of fresh vegetable and fruits

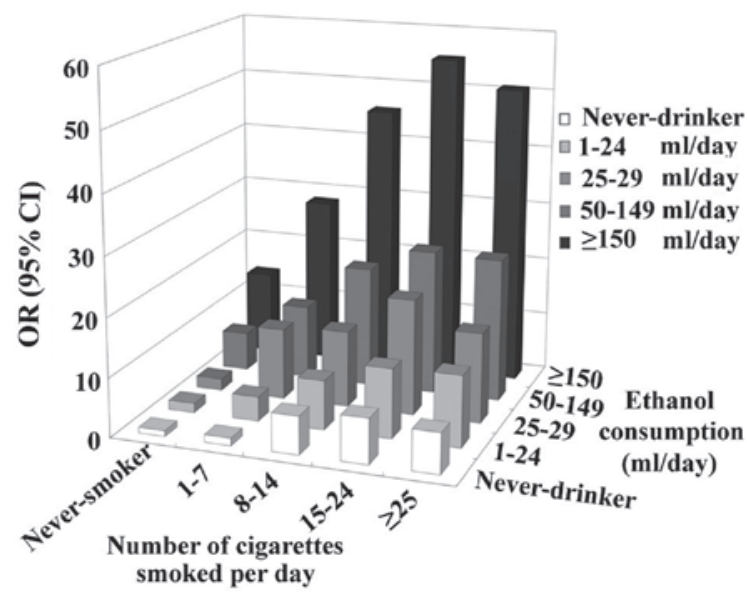

Figure 1. Combined exposure to alcohol consumption and cigarette smoking, and risk of developing esophageal cancer, as reported by Castellsagué et al (19). OR, odds ratio; CI, confidence interval.

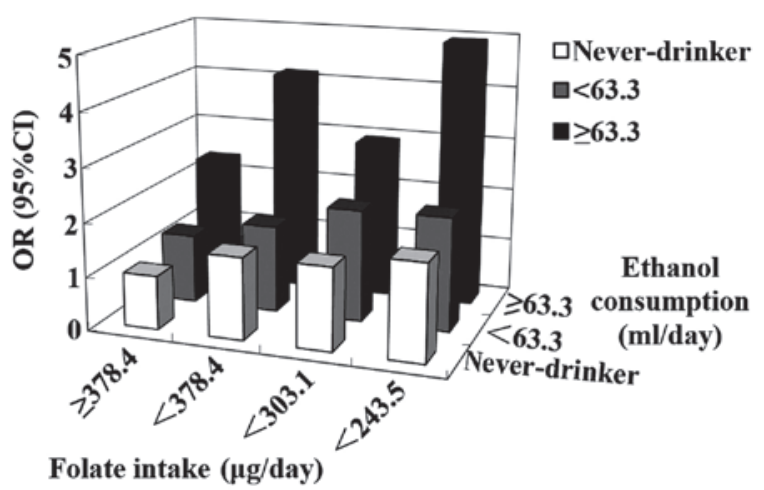

Figure 2. Combined exposure to alcohol consumption and folate intake, and risk of developing oral and pharyngeal cancer, as reported by Matsuo et al (122). OR, odds ratio; CI, confidence interval.

were less likely to develop esophageal cancer (112-115). Among numerous anticarcinogenic nutrients contained in plant foods, folate intake has been widely demonstrated to be closely associated with cancer of the brain, lung, esophagus, pancreas, colorectum, breast, cervix and breast in previous epidemiological studies (116). Three meta-analyses involving worldwide case-control studies conducted between 1988 and 2011 reached a consensus that folate intake may effectively protect individuals from ESCC and EAC, with a pooled OR and relative risk (RR) between 0.50 and $0.66(78,117,118)$. In a large cohort study, a decreased intake of folate compared with the daily median intake ( $405 \mu \mathrm{g})$ demonstrated an inverse association with the risk of developing ESCC, but increased intake showed no association; furthermore, there were no significant associations between dietary folate and risk of EAC (119). One hypothesis proposed that folate intake was not linearly associated with cancer risk, with a protective effect only in moderate folate intake but no protection or even tumor promotion in low or excessive ingestion (120). In that study, the cohort had a relatively high median of folate consumption, which may explain this inconsistency with other studies.

A significant interaction has been observed between folate and alcohol intake in upper digestive tract cancer. In 
Table I. Interaction between alcohol consumption and gene polymorphisms in the risk of esophageal cancer.

Odds ratio/relative risk (95\% confidence interval)

\begin{tabular}{|c|c|c|c|c|c|}
\hline Genes & Gene polymorphisms ${ }^{\mathrm{a}}$ & Alcohol consumption $^{\mathrm{b}}$ & Synergism $^{c}$ & First author, year & Refs. \\
\hline \multirow[t]{4}{*}{ ADH1B*1 } & $4.25(0.41-43.80)$ & $7.01(3.77-13.00)$ & $38.60(13.3-113.00)$ & Yokoyama, 2002 & (41) \\
\hline & $2.37(1.40-4.01)$ & $6.21(2.39-16.30)$ & $25.20(10.90-53.40)$ & Zhang, 2010 & $(42)$ \\
\hline & $0.97(0.21-3.62)$ & $2.72(0.55-79.60)$ & $3.70(0.34-282.00)$ & Wang, 2011 & (44) \\
\hline & $1.39(0.84-2.31)$ & $1.67(1.18-2.37)$ & $3.58(2.20-5.84)$ & $\mathrm{Wu}, 2013$ & $(45)$ \\
\hline $\mathrm{ADH} 1 \mathrm{C} * 2$ & $0.81(0.17-3.99)$ & $6.64(3.66-12.10)$ & $23.80(7.67-74.10)$ & Yokoyama, 2002 & (41) \\
\hline \multirow[t]{4}{*}{$\mathrm{ALDH} 2 * 2$} & $1.44(0.22-9.54)$ & $10.40(2.85-37.80)$ & $88.90(24.0-74.10)$ & Yokoyama, 2002 & (41) \\
\hline & $1.70(1.05-2.75)$ & $4.22(2.03-8.77)$ & $21.50(6.44-71.60)$ & Zhang, 2010 & $(42)$ \\
\hline & $1.59(0.87-3.71)$ & $1.03(0.07-27.50)$ & $7.05(0.48-331.00)$ & Wang, 2011 & (44) \\
\hline & $0.74(0.53-1.02)$ & $1.35(0.99-1.85)$ & $2.34(1.52-3.61)$ & Wu, 2013 & $(45)$ \\
\hline \multirow[t]{2}{*}{ CYP2E1*C1 } & $0.56(0.20-1.59)$ & $1.93(0.43-2.41)$ & $7.64(2.82-11.30)$ & Guo, 2008 & (62) \\
\hline & $2.70(1.31-5.57)$ & $1.94(0.82-4.60)$ & $7.10(3.44-14.70)$ & Qin, 2008 & (63) \\
\hline MTHFR C677T & $2.19(1.03-4.73)$ & $3.42(1.28-8.93)$ & $5.77(2.11-15.70)$ & Zhao, 2011 & $(75)$ \\
\hline GSTM1 deletion & $1.56(0.80-3.04)$ & $2.74(1.01-7.55)$ & $6.27(2.30-17.70)$ & Wang, 2004 & (82) \\
\hline CYP1A1 Val/Val & $2.01(0.94-3.43)$ & $3.02(1.31-7.03)$ & $7.71(2.39-32.20)$ & Wang, 2004 & (82) \\
\hline
\end{tabular}

andividuals who are homozygotes or heterozygotes for one of the listed genes but not alcohol-drinkers. 'Individuals who are heavy drinkers but non-carriers of one of the listed genes, or heterozygotes for that gene. ${ }^{c}$ Synergism between gene polymorphisms and alcohol consumption in individuals who are heavy alcohol-drinkers and homozygotes or heterozygotes for one of the listed genes. ADH, alcohol dehydrogenase; ALDH, aldehyde dehydrogenase; CYP, cytochrome P450; MTHFR, methylenetetrahydrofolate reductase; GST, glutathione S-transferase.

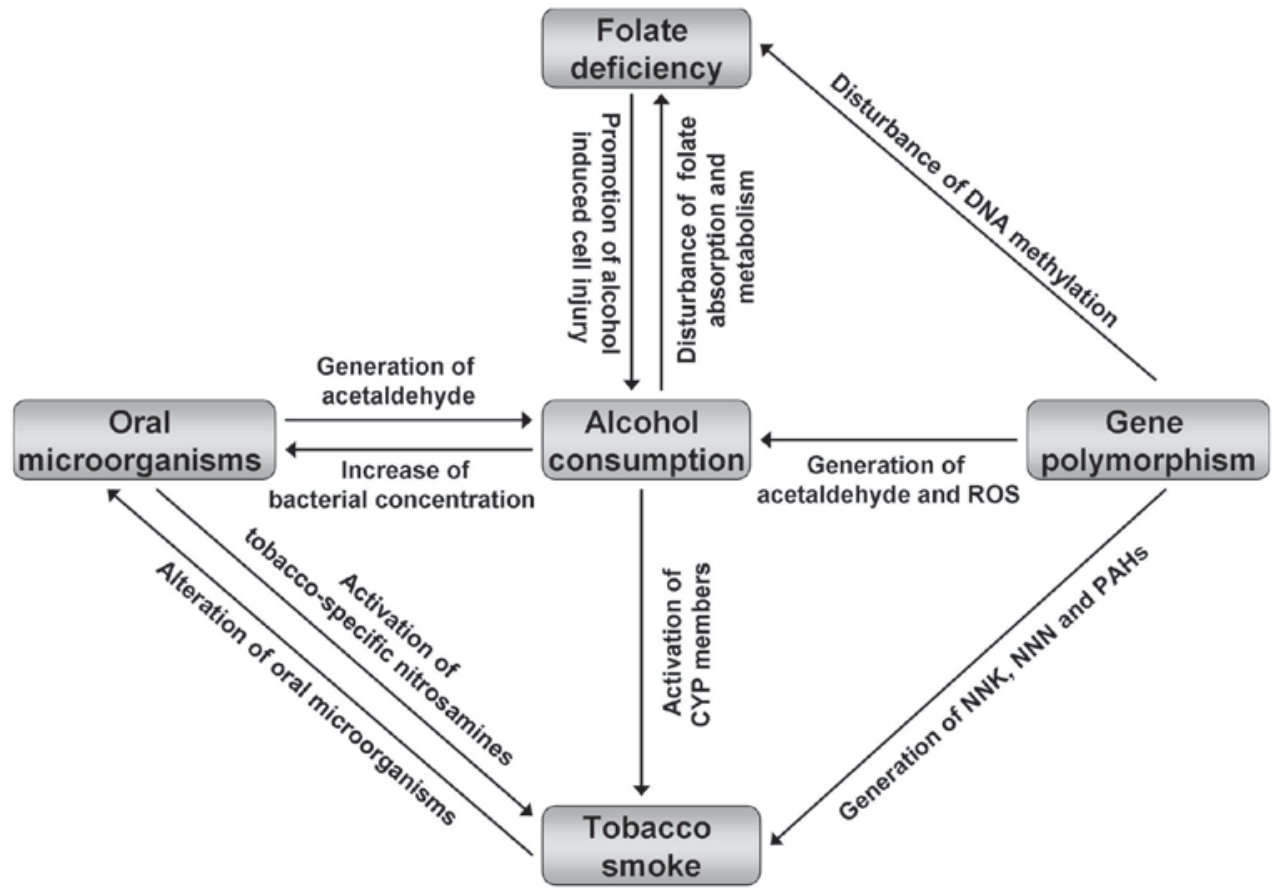

Figure 3. Interactions between alcohol consumption and its corresponding factors. ROS, reactive oxygen species; CYP, cytochrome P450; PAHs, polycyclic aromatic hydrocarbons; NNK, 4-(methylnitrosamino)-1-(3-pyridyl)-1-butanone; NNN, N-nitrosonornicotine.

the case-control study by Ibiebele et al (121), individuals with increased alcohol and decreased folate intake demonstrated a 3-fold OR of ESCC compared with individuals with decreased alcohol and increased folate intake. Matsuo et al (122) reported a similar association in oral and pharyngeal cancer (Fig. 2).
Another large prospective cohort study additionally confirmed the antagonistic interaction between alcohol and folate intake in oral cancer (123).

Folate is important in DNA metabolism, since it mediates the synthesis of $\mathrm{S}$-adenosylmethionine, a methyl 
donor used in biological methylation reactions and de novo deoxynucleoside triphosphate synthesis (116). Folate depletion may be oncogenic through altered DNA/RNA methylation, disruption of DNA integrity and disruption of DNA repair (116). Alcohol ingestion is a primary cause of folate deficiency $(124,125)$. In addition to dietary inadequacy, alcohol may decrease internal folate levels through intestinal malabsorption, decreased hepatic storage and increased renal excretion $(124,125)$. Folate homeostasis depends on transporter proteins, including reduced folate carrier, proton-coupled folate transporter, folate-binding protein, mitochondrial folate transporter and enzymes such as folylpolyglutamate synthetase (126-129). Chronic ethanol exposure may downregulate gene expression, thus impairing the transportation of folate across membranes (126-129). With the exception of causing folate deficiency, ethanol intake interferes widely in folate-dependent intermediary metabolism by inhibiting enzymes in the one-carbon metabolism, particularly methionine synthase and its associated products of metabolism, thus disturbing the synthesis of nucleotides (130). By contrast, folate deficiency facilitates the adverse effects of alcohol in methionine metabolism and promotes alcohol-induced oxidative cell injury (124).

\section{Conclusion}

Alcohol consumption significantly increases the risk of esophageal cancer, exhibiting a dose-response association with daily intake and an altered efficiency in various beverage types, populations and cancer subtypes. Gene polymorphisms, tobacco smoking, oral microorganisms and folate deficiency act as collaborators with concurrent alcohol use (Fig. 3). Current evidence suggests that, rather than mere alcohol consumption, the synergy of alcohol consumption and corresponding factors is important for the development of esophageal cancer. Therefore, quitting alcohol drinking and tobacco smoking, maintaining an adequate oral hygiene and ingesting adequate levels of plant foods may effectively protect high-risk individuals from developing esophageal cancer.

\section{References}

1. Ferlay J, Soerjomataram I, Dikshit R, Eser S, Mathers C, Rebelo M, Parkin DM, Forman D and Bray F: Cancer incidence and mortality worldwide: Sources, methods and major patterns in GLOBOCAN 2012. Int J Cancer 136: E359-E386, 2015.

2. Danaei G, Vander Hoorn S, Lopez AD, Murray CJ and Ezzati M; Comparative Risk Assessment collaborating group (Cancers) Causes of cancer in the world: Comparative risk assessment of nine behavioural and environmental risk factors. Lancet 366 : 1784-1793, 2005

3. Wang JB, Fan JH, Liang H, Li J, Xiao HJ, Wei WQ, Dawsey SM, Qiao YL and Boffetta P: Attributable causes of esophageal cancer incidence and mortality in China. PLoS One 7: e42281, 2012.

4. Engel LS, Chow WH, Vaughan TL, Gammon MD, Risch HA, Stanford JL, Schoenberg JB, Mayne ST, Dubrow R, Rotterdam H, et al: Population attributable risks of esophageal and gastric cancers. J Natl Cancer Inst 95: 1404-1413, 2003.

5. Jones L, Bates G, McCoy E and Bellis MA: Relationship between alcohol-attributable disease and socioeconomic status, and the role of alcohol cons-umption in this relationship: A systematic review and meta-analysis. BMC Public Health 15: $400,2015$.
6. Lim SS, Vos T, Flaxman AD, Danaei G, Shibuya K, Adair-Rohani H, Amann M, Anderson HR, Andrews KG, Aryee M, Atkinson C, et al: A comparative risk assessment of burden of disease and injury attributable to 67 risk factors and risk factor clusters in 21 regions, 1990-2010: A systematic analysis for the Global Burden of Disease Study 2010. Lancet 380: 2224-2260, 2012.

7. Pöschl G and Seitz HK: Alcohol and cancer. Alcohol Alcohol 39: 155-165, 2004.

8. Brooks PJ and Theruvathu JA: DNA adducts from acetaldehyde: Implications for alcohol-related carcinogenesis. Alcohol 35: 187-193, 2005.

9. Seitz HK and Stickel F: Molecular mechanisms of alcohol-mediated carcinogenesis. Nat Rev Cancer 7: 599-612, 2007.

10. Oze I, Matsuo K, Wakai K, Nagata C, Mizoue T, Tanaka K, Tsuji I, Sasazuki S, Inoue M and Tsugane S; Research Group for the Development and Evaluation of Cancer Prevention Strategies in Japan: Alcohol drinking and esophageal cancer risk: An evaluation based on a systematic review of epidemiologic evidence among the Japanese population. Jpn J Clin Oncol 41: 677-692, 2011.

11. Islami F, Fedirko V, Tramacere I, Bagnardi V, Jenab M, Scotti L, Rota M, Corrao G, Garavello W, Schüz J, et al: Alcohol drinking and esophageal squamous cell carcinoma with focus on light-drinkers and never-smokers: A systematic review and meta-analysis. Int J Cancer 129: 2473-2484, 2011.

12. Kumagai N, Wakai T, Akazawa K, Ling Y, Wang S, Shan B, Okuhara Y, Hatakeyama Y and Kataoka H: Heavy alcohol intake is a risk factor for esophageal squamous cell carcinoma among middle-aged men: A case-control and simulation study. Mol Clin Oncol 1: 811-816, 2013.

13. Gao YT, McLaughlin JK, Blot WJ, Ji BT, Benichou J, Dai Q and Fraumeni JF Jr: Risk factors for esophageal cancer in Shanghai, China. I. Role of cigarette smoking and alcohol drinking. Int J Cancer 58: 192-196, 1994.

14. Zambon P, Talamini R, La Vecchia C, Dal Maso L, Negri E, Tognazzo S, Simonato L and Franceschi S: Smoking, type of alcoholic beverage and squamous-cell oesophageal cancer in northern Italy. Int J Cancer 86: 144-149, 2000.

15. Lubin JH, Cook MB, Pandeya N, Vaughan TL, Abnet CC, Giffen C, Webb PM, Murray LJ, Casson AG, Risch HA, et al: The importance of exposure rate on odds ratios by cigarette smoking and alcohol consumption for esophageal adenocarcinoma and squamous cell carcinoma in the Barrett's Esophagus and Esophageal Adenocarcinoma Consortium. Cancer Epidemiol 36: 306-316, 2012.

16. Polesel J, Dal Maso L, Bagnardi V, Zucchetto A, Zambon A, Levi F, La Vecchia C and Franceschi S: Estimating dose-response relationship between ethanol and risk of cancer using regression spline models. Int J Cancer 114: 836-841, 2005.

17. Steevens J, Schouten LJ, Goldbohm RA and van den Brandt PA: Alcohol consumption, cigarette smoking and risk of subtypes of oesophageal and gastric cancer: A prospective cohort study. Gut 59: 39-48, 2010.

18. Fan Y, Yuan JM, Wang R, Gao YT and Yu MC: Alcohol, tobacco, and diet in relation to esophageal cancer: The Shanghai Cohort Study. Nutr Cancer 60: 354-363, 2008.

19. Castellsagué X, Muñoz N, De Stefani E, Victora CG, Castelletto R, Rolón PA and Quintana MJ: Independent and joint effects of tobacco smoking and alcohol drinking on the risk of esophageal cancer in men and women. Int J Cancer 82: 657-664, 1999.

20. Holmes RS and Vaughan TL: Epidemiology and pathogenesis of esophageal cancer. Semin Radiat Oncol 17: 2-9, 2007.

21. Linderborg K, Joly JP, Visapää JP and Salaspuro M: Potential mechanism for Calvados-related oesophageal cancer. Food Chem Toxicol 46: 476-479, 2008.

22. Bosetti C, La Vecchia C, Negri E and Franceschi S: Wine and other types of alcoholic beverages and the risk of esophageal cancer. Eur J Clin Nutr 54: 918-920, 2000.

23. Launoy G, Milan C, Day NE, Faivre J, Pienkowski P and Gignoux M: Oesophageal cancer in France: Potential importance of hot alcoholic drinks. Int J Cancer 71: 917-923, 1997.

24. Neuhouser ML: Dietary flavonoids and cancer risk: Evidence from human population studies. Nutr Cancer 50: 1-7, 2004.

25. Wu M, Zhao JK, Zhang ZF, Han RQ, Yang J, Zhou JY, Wang XS, Zhang XF, Liu AM, van't Veer P, et al: Smoking and alcohol drinking increased the risk of esophageal cancer among Chinese men but not women in a high-risk population. Cancer Causes Control 22: 649-657, 2011. 
26. Vioque J, Barber X, Bolumar F, Porta M, Santibáñez M, de la Hera MG and Moreno-Osset E; PANESOES Study Group: Esophageal cancer risk by type of alcohol drinking and smoking: A case-control study in Spain. BMC Cancer 8: 221, 2008.

27. Wang Z, Tang L, Sun G, Tang Y, Xie Y, Wang S, Hu X, Gao W, Cox SB and Wang JS: Etiological study of esophageal squamous cell carcinoma in an endemic region: A population-based case control study in Huaian, China. BMC Cancer 6: 287, 2006.

28. Tran GD, Sun XD, Abnet CC, Fan JH, Dawsey SM, Dong ZW, Mark SD, Qiao YL and Taylor PR: Prospective study of risk factors for esophageal and gastric cancers in the Linxian general population trial cohort in China. Int J Cancer 113: 456-463, 2005

29. Freedman ND, Murray LJ, Kamangar F, Abnet CC, Cook MB Nyrén O, Ye W, Wu AH, Bernstein L, Brown LM, et al: Alcohol intake and risk of oesophageal adenocarcinoma: A pooled analysis from the BEACON Consortium. Gut 60: 1029-1037, 2011.

30. Steevens J, Schouten LJ, Driessen AL, Huysentruyt CJ Keulemans YC, Goldbohm RA and van den Brandt PA: A prospective cohort study on overweight, smoking, alcohol consumption, and risk of Barrett's esophagus. Cancer Epidemiol Biomarkers Prev 20: 345-358, 2011.

31. Tramacere I, Pelucchi C, Bagnardi V, Rota M, Scotti L, Islami F, Corrao G, Boffetta P, La Vecchia C and Negri E: A meta-analysis on alcohol drinking and esophageal and gastric cardia adenocarcinoma risk. Ann Oncol 23: 287-297, 2012.

32. Thrift AP, Kramer JR, Richardson PA and El-Serag HB: No significant effects of smoking or alcohol consumption on risk of Barrett's esophagus. Dig Dis Sci 59: 108-116, 2014.

33. Akiyama T, Inamori M, Iida $\mathrm{H}$, Mawatari $\mathrm{H}$, Endo $\mathrm{H}$, Hosono $\mathrm{K}$ Yoneda K, Fujita K, Yoneda M, Takahashi H, et al: Alcohol consumption is associated with an increased risk of erosive esophagitis and Barrett's epithelium in Japanese men. BMC Gastroenterol 8: 58, 2008.

34. Siewert JR and Ott K: Are squamous and adenocarcinomas of the esophagus the same disease? Semin Radiat Oncol 17: 38-44, 2007.

35. Druesne-Pecollo N, Tehard B, Mallet Y, Gerber M, Norat T, Hercberg S and Latino-Martel P: Alcohol and genetic polymorphisms: Effect on risk of alcohol-related cancer. Lancet Oncol 10: 173-180, 2009.

36. Edenberg HJ: The genetics of alcohol metabolism: Role of alcohol dehydrogenase and aldehyde dehydrogenase variants. Alcohol Res Health 30: 5-13, 2007.

37. Brennan P,Lewis S, Hashibe M, Bell DA, Boffetta P, Bouchardy C, Caporaso N, Chen C, Coutelle C, Diehl SR, et al: Pooled analysis of alcohol dehydrogenase genotypes and head and neck cancer: A HuGE review. Am J Epidemiol 159: 1-16, 2004.

38. Boffetta $\mathrm{P}$ and Hashibe M: Alcohol and cancer. Lancet Oncol 7: 149-156, 2006

39. Bosron WF and Li TK: Genetic polymorphism of human liver alcohol and aldehyde dehydrogenases, and their relationship to alcohol metabolism and alcoholism. Hepatology 6: 502-510, 1986.

40. Osier M, Pakstis AJ, Kidd JR, Lee JF, Yin SJ, Ko HC, Edenberg HJ, Lu RB and Kidd KK: Linkage disequilibrium at the ADH2 and ADH3 loci and risk of alcoholism. Am J Hum Genet 64: 1147-1157, 1999.

41. Yokoyama A, Kato H, Yokoyama T, Tsujinaka T, Muto M, Omori T, Haneda T, Kumagai Y, Igaki H, Yokoyama M, et al: Genetic polymorphisms of alcohol and aldehyde dehydrogenases and glutathione S-transferase M1 and drinking, smoking, and diet in Japanese men with esophageal squamous cell carcinoma. Carcinogenesis 23: 1851-1859,2002.

42. Zhang GH, Mai RQ and Huang B: Meta-analysis of ADH1B and ALDH2 polymorphisms and esophageal cancer risk in China. World J Gastroenterol 16: 6020-6025, 2010.

43. Lee CH, Lee JM, Wu DC, Goan YG, Chou SH, Wu IC, Kao EL, Chan TF, Huang MC, Chen PS, et al: Carcinogenetic impact of $\mathrm{ADH} 1 \mathrm{~B}$ and ALDH2 genes on squamous cell carcinoma risk of the esophagus with regard to the consumption of alcohol, tobacco and betel quid. Int J Cancer 122: 1347-1356, 2008.

44. Wang Y, Ji R, Wei X, Gu L, Chen L, Rong Y, Wang R, Zhang Z, Liu B and Xia S: Esophageal squamous cell carcinoma and ALDH2 and ADH1B polymorphisms in Chinese females. Asian Pac J Cancer Prev 12: 2065-2068, 2011.

45. Wu M, Chang SC, Kampman E, Yang J, Wang XS, Gu XP, Han RQ, Liu AM, Wallar G, Zhou JY, et al: Single nucleotide polymorphisms of ADH1B, ADH1C and ALDH2 genes and esophageal cancer: A population-based case-control study in China. Int J Cancer 132: 1868-1877, 2013.
46. Muto M, Nakane M, Hitomi Y, Yoshida S, Sasaki S, Ohtsu A, Yoshida S, Ebihara S and Esumi H: Association between aldehyde dehydrogenase gene polymorphisms and the phenomenon of field cancerization in patients with head and neck cancer. Carcinogenesis 23: 1759-1765, 2002.

47. Terry MB, Gammon MD, Zhang FF, Vaughan TL, Chow WH, Risch HA, Schoenberg JB, Mayne ST, Stanford JL, West AB, et al: Alcohol dehydrogenase 3 and risk of esophageal and gastric adenocarcinomas. Cancer Causes Control 18: 1039-1046, 2007.

48. Hashibe $M$, Boffetta $P$, Zaridze D, Shangina O, Szeszenia-Dabrowska N, Mates D, Janout V, Fabiánová E, Bencko V, Moullan N, et al: Evidence for an important role of alcohol- and aldehyde-metabolizing genes in cancers of the upper aerodigestive tract. Cancer Epidemiol Biomarkers Prev 15: 696-703, 2006

49. Jairam S and Edenberg HJ: An enhancer-blocking element regulates the cell-specific expression of alcohol dehydrogenase 7 . Gene 547: 239-244, 2014

50. Wang J, Wei J, Xu X, Pan W, Ge Y, Zhou C, Liu C, Gao J, Yang M and Mao W: Replication study of ESCC susceptibility genetic polymorphisms locating in the ADH1B-ADH1C-ADH7 cluster identified by GWAS. PLoS One 9: e94096, 2014.

51. Hashibe M, McKay JD, Curado MP, Oliveira JC, Koifman S, Koifman R, Zaridze D, Shangina O, Wünsch-Filho V, Eluf-Neto J, et al: Multiple ADH genes are associated with upper aerodigestive cancers. Nat Genet 40: 707-709, 2008.

52. Oze I, Matsuo K, Suzuki T, Kawase T, Watanabe M, Hiraki A, Ito H, Hosono S, Ozawa T, Hatooka S, et al: Impact of multiple alcohol dehydrogenase gene polymorphisms on risk of upper aerodigestive tract cancers in a Japanese population. Cancer Epidemiol Biomarkers Prev 18: 3097-3102, 2009.

53. Li H, Borinskaya S, Yoshimura K, Kal'ina N, Marusin A, Stepanov VA, Qin Z, Khaliq S, Lee MY, Yang Y, et al: Refined geographic distribution of the oriental ALDH2*504Lys (nee 487Lys) variant. Ann Hum Genet 73: 335-345, 2009.

54. Mizoi Y, Yamamoto K, Ueno Y, Fukunaga T and Harada S: Involvement of genetic polymorphism of alcohol and aldehyde dehydrogenases in individual variation of alcohol metabolism. Alcohol Alcohol 29: 707-710, 1994.

55. Yokoyama A, Muramatsu T, Ohmori T, Makuuchi H, Higuchi S, Matsushita S, Yoshino K, Maruyama K, Nakano M and Ishii H: Multiple primary esophageal and concurrent upper aerodigestive tract cancer and the aldehyde dehydrogenase-2 genotype of Japanese alcoholics. Cancer 77: 1986-1990, 1996

56. Yokoyama A, Muramatsu T, Ohmori T, Yokoyama T, Okuyama K, Takahashi H, Hasegawa Y, Higuchi S, Maruyama K, Shirakura K and Ishii H: Alcohol-related cancers and aldehyde dehydrogenase-2 in Japanese alcoholics. Carcinogenesis 19: 1383-1387, 1998

57. Lewis SJ and Smith GD: Alcohol, ALDH2, and esophageal cancer: A meta-analysis which illustrates the potentials and limitations of a Mendelian randomization approach. Cancer Epidemiol Biomarkers Prev 14: 1967-1971, 2005.

58. Yokoyama T, Yokoyama A, Kato H, Tsujinaka T, Muto M, Omori T, Haneda T, Kumagai Y, Igaki H, Yokoyama M, et al: Alcohol flushing, alcohol and aldehyde dehydrogenase genotypes, and risk for esophageal squamous cell carcinoma in Japanese men. Cancer Epidemiol Biomarkers Prev 12: 1227-1233, 2003.

59. Brooks PJ, Enoch MA, Goldman D, Li TK and Yokoyama A: The alcohol flushing response: An unrecognized risk factor for esophageal cancer from alcohol consumption. PLoS Med 6: e50, 2009.

60. Lewis DF, Bird MG and Parke DV: Molecular modelling of CYP2E1 enzymes from rat, mouse and man: An explanation for species differences in butadiene metabolism and potential carcinogenicity, and rationalization of CYP2E substrate specificity. Toxicology 118: 93-113, 1997.

61. Gonzalez FJ: Role of cytochromes P450 in chemical toxicity and oxidative stress: Studies with CYP2E1. Mutat Res 569: 101-110, 2005.

62. Guo YM, Wang Q, Liu YZ, Chen HM, Qi Z and Guo QH: Genetic polymorphisms in cytochrome P4502E1, alcohol and aldehyde dehydrogenases and the risk of esophageal squamous cell carcinoma in Gansu Chinese males. World J Gastroenterol 14: 1444-1449, 2008.

63. Qin JM, Yang L, Chen B, Wang XM, Li F, Liao PH and He L: Interaction of methylenetetrahydrofolate reductase C677T, cytochrome P4502E1 polymorphism and environment factors in esophageal cancer in Kazakh population. World J Gastroenterol 14: 6986-6992,2008 
64. Morita S, Yano M,ShiozakiH, Tsujinaka T, Ebisui C, Morimoto T, Kishibuti M, Fujita J, Ogawa A, Taniguchi M, et al: CYP1A1, CYP2E1 and GSTM1 polymorphisms are not associated with susceptibility to squamous-cell carcinoma of the esophagus. Int J Cancer 71: 192-195, 1997.

65. Lucas D, Ménez C, Floch F, Gourlaouen Y, Sparfel O, Joannet I, Bodénez P, Jezequel J, Gouérou H, Berthou F, et al: Cytochromes P4502E1 and P4501A1 genotypes and susceptibility to cirrhosis or upper aerodigestive tract cancer in alcoholic caucasians. Alcohol Clin Exp Res 20: 1033-1037, 1996.

66. Rossini A, Rapozo DC, Soares Lima SC, Guimarães DP, Ferreira MA, Teixeira R, Kruel CD, Barros SG, Andreollo NA, Acatauassú R, et al: Polymorphisms of GSTP1 and GSTT1, but not of CYP2A6, CYP2E1 or GSTM1, modify the risk for esophageal cancer in a western population. Carcinogenesis 28: 2537-2542, 2007.

67. Dura P, Berkers T, van Veen EM, Salomon J, te Morsche RH, Roelofs HM, Kristinsson JO, Wobbes T, Witteman BJ, Tan AC, et al: Polymorphisms in alcohol-metabolizing enzymes and esophageal carcinoma susceptibility: A Dutch Caucasian case-control study. J Hum Genet 58: 742-748, 2013.

68. Trimmer EE: Methylenetetrahydrofolate reductase: Biochemical characterization and medical significance. Curr Pharm Des 19: 2574-2593, 2013.

69. Ly A, Hoyt L, Crowell J and Kim YI: Folate and DNA methylation. Antioxid Redox Sign 17: 302-326, 2012.

70. Frosst P, Blom HJ, Milos R, Goyette P, Sheppard CA, Matthews RG, Boers GJ, den Heijer M, Kluijtmans LA and van den Heuvel LP: A candidate genetic risk factor for vascular disease: A common mutation in methylenetetrahydrofolate reductase. Nat Genet 10: 111-113, 1995.

71. Stern LL, Mason JB, Selhub J and Choi SW: Genomic DNA hypomethylation, a characteristic of most cancers, is present in peripheral leukocytes of individuals who are homozygous for the C677T polymorphism in the methylenetetrahydrofolate reductase gene. Cancer Epidemiol Biomarkers Prev 9: 849-853, 2000.

72. Goyette P, Sumner JS, Milos R, Duncan AM, Rosenblatt DS, Matthews RG and Rozen R: Human methylenetetrahydrofolate reductase: Isolation of cDNA, mapping and mutation identification. Nat Genet 7: 195-200, 1994.

73. Bailey LB and Gregory JF III: Polymorphisms of methylenetetrahydrofolate reductase and other enzymes: Metabolic significance, risks and impact on folate requirement. J Nutr 129: 919-922, 1999.

74.Li QD, Li H, Wang MS, Diao TY, Zhou ZY, Fang QX, Yang FY and Li QH: Multi-susceptibility genes associated with the risk of the development stages of esophageal squamous cell cancer in Feicheng County. BMC Gastroenterol 11: 74, 2011.

75.Zhao P, Lin F, Li Z, Lin B, Lin J and Luo R: Folate intake, methylenetetrahydrofolate reductase polymorphisms, and risk of esophageal cancer. Asian Pac J Cancer Prev 12: 2019-2023, 2011.

76. Li D, Diao Y, Li H, Fang X and Li H: Association of the polymorphisms of MTHFR C677T, VDR C352T and MPO G463A with risk for esophageal squamous cell dysplasia and carcinoma. Arch Med Res 39: 594-600, 2008.

77.Langevin SM, Lin D, Matsuo K, Gao CM, Takezaki T, Stolzenberg-Solomon RZ, Vasavi M, Hasan Q and Taioli E: Review and pooled analysis of studies on MTHFR C677T polymorphism and esophageal cancer. Toxicol Lett 184: 73-80, 2009.

78. Liu YX, Wang B, Wan MH, Tang WF, Huang FK and Li C: Meta-analysis of the relationship between the metholenetetrahydrofolate reductase C677T genetic polymorphism, folate intake and esophageal cancer. Asian Pac J Cancer Prev 12: 247-252, 2011

79. Yang CX, Matsuo K, Ito H, Shinoda M, Hatooka S, Hirose K, Wakai K, Saito T, Suzuki T, Maeda T and Tajima K Gene-environment interactions between alcohol drinking and the MTHFR C677T polymorphism impact on esophageal cancer risk: Results of a case-control study in Japan. Carcinogenesis 26 . $1285-1290,2005$

80. Song C, Xing D, Tan W, Wei Q and Lin D: Methylenetetrahydrofolate reductase polymorphisms increase risk of esophageal squamous cell carcinoma in a Chinese population. Cancer Res 61: 3272-3275, 2001.

81. Hiyama T, Yoshihara M, Tanaka S and Chayama K: Genetic polymorphisms and esophageal cancer risk. Int J Cancer 121: 1643-1658, 2007.
82. Wang AH, Sun CS, Li LS, Huang JY, Chen QS and Xu DZ Genetic susceptibility and environmental factors of esophageal cancer in Xi'an. World J Gastroenterol 10: 940-944, 2004.

83. Li D, Dandara C and Parker MI: The $341 \mathrm{C} / \mathrm{T}$ polymorphism in the GSTP1 gene is associated with increased risk of oesophageal cancer. BMC Genet 11: 47, 2010.

84. Secretan B, Straif K, Baan R, Grosse Y, El Ghissassi F, Bouvard V, Benbrahim-Tallaa L, Guha N, Freeman C, Galichet L and Cogliano V; WHO International Agency for Research on Cancer Monograph Working Group: A review of human carcinogens - Part E: Tobacco, areca nut, alcohol, coal smoke, and salted fish. Lancet Oncol 10: 1033-1034, 2009.

85. Littleton J, Barron S, Prendergast $M$ and Nixon SJ: Smoking kills (alcoholics)! Shouldn't we do something about it? Alcohol Alcohol 42: 167-173, 2007.

86. Prabhu A, Obi KO and Rubenstein JH: The synergistic effects of alcohol and tobacco consumption on the risk of esophageal squamous cell carcinoma: A meta-analysis. Am J Gastroenterol 109: 822-827, 2014.

87. Yaegashi Y, Onoda T, Morioka S, Hashimoto T, Takeshita T, Sakata K and Tamakoshi A: Joint effects of smoking and alcohol drinking on esophageal cancer mortality in Japanese men: Findings from the Japan collaborative cohort study. Asian Pac J Cancer Prev 15: 1023-1029, 2014

88. Chen J, Zhang N, Wakai T, Wei L, He Y, Kumagai N, Kitsu K, Wang $\mathrm{S}$ and Akazawa K: Effect of the interaction between the amount and duration of alcohol consumption and tobacco smoking on the risk of esophageal cancer: A case-control study. Exp Ther Med 1: 991-997, 2010

89. Yang G, Fan L, Tan J, Qi G, Zhang Y, Samet JM, Taylor CE, Becker K and Xu J: Smoking in China: Findings of the 1996 National Prevalence Survey. JAMA 282: 1247-1253, 1999.

90. Toh Y, Oki E, Ohgaki K, Sakamoto Y, Ito S, Egashira A, Saeki H, Kakeji Y, Morita M, Sakaguchi Y, et al: Alcohol drinking, cigarette smoking, and the development of squamous cell carcinoma of the esophagus: Molecular mechanisms of carcinogenesis. Int J Clin Oncol 15: 135-144, 2010.

91.Lopes CF, de Angelis BB, Prudente HM, de Souza BV, Cardoso SV and de Azambuja Ribeiro RI: Concomitant consumption of marijuana, alcohol and tobacco in oral squamous cell carcinoma development and progression: Recent advances and challenges. Arch Oral Biol 57: 1026-1033, 2012.

92. Salaspuro M: Interactions of alcohol and tobacco in gastrointestinal cancer. J Gastroenterol Hepatol 28: 1252, 2013.

93. Simanowski UA, Suter P, Stickel F, Maier H, Waldherr R, Smith D, Russell RM and Seitz HK: Esophageal epithelial hyperproliferation following long-term alcohol consumption in rats: Effects of age and salivary gland function. J Natl Cancer Inst 85: 2030-2033, 1993

94. Maier H, Weidauer H, Zöller J, Seitz HK, Flentje M, Mall G and Born IA: Effect of chronic alcohol consumption on the morphology of the oral mucosa. Alcohol Clin Exp Res 18: 387-391, 1994

95. Homann N, Kärkkäinen P, Koivisto T, Nosova T, Jokelainen K and Salaspuro M: Effects of acetaldehyde on cell regeneration and differentiation of the upper gastrointestinal tract mucosa. J Natl Cancer Inst 89: 1692-1697, 1997.

96. Homann N, Jousimies-Somer H, Jokelainen K, Heine R and Salaspuro M: High acetaldehyde levels in saliva after ethanol consumption: Methodological aspects and pathogenetic implications. Carcinogenesis 18: 1739-1743, 1997.

97. Yokoyama A, Tsutsumi E, Imazeki H, Suwa Y, Nakamura C and Yokoyama T: Contribution of the alcohol dehydrogenase-1B genotype and oral microorganisms to high salivary acetaldehyde concentrations in Japanese alcoholic men. Int J Cancer 121: 1047-1054, 2007

98. Maier H, Born IA, Veith S, Adler D and Seitz HK: The effect of chronic ethanol consumption on salivary gland morphology and function in the rat. Alcohol Clin Exp Res 10: 425-427, 1986.

99. Salaspuro MP: Acetaldehyde, microbes, and cancer of the digestive tract. Crit Rev Clin Lab Sci 40: 183-208, 2003.

100. Salaspuro V and Salaspuro M: Synergistic effect of alcohol drinking and smoking on in vivo acetaldehyde concentration in saliva. Int J Cancer 111: 480-483, 2004

101. Holmstrup P and Bessermann M: Clinical, therapeutic, and pathogenic aspects of chronic oral multifocal candidiasis. Oral Surg Oral Med Oral Pathol 56: 388-395, 1983.

102. Colman G, Beighton D, Chalk AJ and Wake S: Cigarette smoking and the microbial flora of the mouth. Aust Dent J 21: $111-118,1976$ 
103. Verna L, Whysner J and Williams GM: N-nitrosodiethylamine mechanistic data and risk assessment: Bioactivation, DNA-adduct formation, mutagenicity, and tumor initiation. Pharmacol Ther 71: 57-81, 1996.

104. Shapiro KB, Hotchkiss JH and Roe DA: Quantitative relationship between oral nitrate-reducing activity and the endogenous formation of N-nitrosoamino acids in humans. Food Chem Toxicol 29: 751-755, 1991.

105. Ahn J, Chen CY and Hayes RB: Oral microbiome and oral and gastrointestinal cancer risk. Cancer Causes Control 23: 399-404, 2012.

106.Pavlova SI, Jin L, Gasparovich SR and Tao L: Multiple alcohol dehydrogenases but no functional acetaldehyde dehydrogenase causing excessive acetaldehyde production from ethanol by oral streptococci. Microbiology 159: 1437-1446, 2013

107. Muto M, Hitomi Y, Ohtsu A, Shimada H, Kashiwase Y, Sasaki H, Yoshida S and Esumi H: Acetaldehyde production by non-pathogenic Neisseria in human oral microflora: Implications for carcinogenesis in upper aerodigestive tract. Int J Cancer 88: 342-350, 2000.

108. Väkeväinen S, Tillonen J, Blom M, Jousimies-Somer H and Salaspuro M: Acetaldehyde production and other ADH-related characteristics of aerobic bacteria isolated from hypochlorhydric human stomach. Alcohol Clin Exp Res 25: 421-426, 2001.

109. Homann N, Tillonen J, Meurman JH, Rintamäki H, Lindqvist C, Rautio M, Jousimies-Somer H and Salaspuro M: Increased salivary acetaldehyde levels in heavy drinkers and smokers: A microbiological approach to oral cavity cancer. Carcinogenesis 21: 663-668, 2000 .

110. Homann N, Tillonen J, Rintamäki H, Salaspuro M, Lindqvist C and Meurman JH: Poor dental status increases acetaldehyde production from ethanol in saliva: A possible link to increased oral cancer risk among heavy drinkers. Oral Oncol 37: 153-158, 2001.

111. Tillonen J, Homann N, Rautio M, Jousimies-Somer H and Salaspuro M: Role of yeasts in the salivary acetaldehyde production from ethanol among risk groups for ethanol-associated oral cavity cancer. Alcohol Clin Exp Res 23: 1409-1415, 1999.

112. Tang L, Lee AH, Xu F, Zhang T, Lei J and Binns CW: Fruit and vegetable consumption and risk of esophageal cancer: A case-control study in north-west China. Dis Esophagus 27: 777-782, 2014

113. Jeurnink SM, Büchner FL, Bueno-de-Mesquita HB, Siersema PD, Boshuizen HC, Numans ME, Dahm CC, Overvad K, Tjønneland A, Roswall N, et al: Variety in vegetable and fruit consumption and the risk of gastric and esophageal cancer in the European Prospective Investigation into Cancer and Nutrition. Int J Cancer 131: E963-E973, 2012

114. Lucenteforte E, Garavello W, Bosetti C, Talamini R, Zambon P, Franceschi S, Negri E and La Vecchia C: Diet diversity and the risk of squamous cell esophageal cancer. Int J Cancer 123: 2397-2400, 2008.
115. Freedman ND, Park Y, Subar AF, Hollenbeck AR, Leitzmann MF, Schatzkin A and Abnet CC: Fruit and vegetable intake and esophageal cancer in a large prospective cohort study. Int J Cancer 121: 2753-2760, 2007.

116. Choi SW and Mason JB: Folate and carcinogenesis: An integrated scheme. J Nutr 130: 129-132, 2000.

117. Larsson SC, Giovannucci E and Wolk A: Folate intake, MTHFR polymorphisms, and risk of esophageal, gastric, and pancreatic cancer: A meta-analysis. Gastroenterology 131: 1271-1283, 2006.

118. Tio M, Andrici J, Cox MR and Eslick GD: Folate intake and the risk of upper gastrointestinal cancers: A systematic review and meta-analysis. J Gastroenterol Hepatol 29: 250-258, 2014.

119. Xiao Q, Freedman ND, Ren J, Hollenbeck AR, Abnet CC and Park Y: Intakes of folate, methionine, vitamin B6, and vitamin B12 with risk of esophageal and gastric cancer in a large cohort study. Br J Cancer 110: 1328-1333, 2014.

120. Ulrich CM: Folate and cancer prevention: A closer look at a complex picture. Am J Clin Nutr 86: 271-273, 2007.

121. Ibiebele TI, Hughes MC, Pandeya N, Zhao Z, Montgomery G, Hayward N, Green AC, Whiteman DC and Webb PM; Study of Digestive Health; Australian Cancer Study: High intake of folate from food sources is associated with reduced risk of esophageal cancer in an Australian population. J Nutr 141: 274-283, 2011.

122. Matsuo K, Rossi M, Negri E, Oze I, Hosono S, Ito H, Watanabe M, Yatabe Y, Hasegawa Y, Tanaka H, et al: Folate, alcohol, and aldehyde dehydrogenase 2 polymorphism and the risk of oral and pharyngeal cancer in Japanese. Eur J Cancer Prev 21: 193-198, 2012.

123. Shanmugham JR, Zavras AI, Rosner BA and Giovannucci EL: Alcohol-folate interactions in the risk of oral cancer in women: A prospective cohort study. Cancer Epidemiol Biomarkers Prev 19: 2516-2524, 2010.

124. Halsted CH, Villanueva JA, Devlin AM and Chandler CJ: Metabolic interactions of alcohol and folate. J Nutr 132 (Suppl 8): 2367S-2372S, 2002

125. Hamid A, Wani NA and Kaur J: New perspectives on folate transport in relation to alcoholism-induced folate malabsorption - association with epigenome stability and cancer development. FEBS J 276: 2175-2191, 2009.

126. Biswas A, Senthilkumar SR and Said HM: Effect of chronic alcohol exposure on folate uptake by liver mitochondria. Am J Physiol Cell Physiol 302: C203-C209, 2012.

127. Wani NA, Hamid A and Kaur J: Alcohol-associated folate disturbances result in altered methylation of folate-regulating genes. Mol Cell Biochem 363: 157-166, 2012.

128. Said HM, Mee L, Sekar VT, Ashokkumar B and Pandol SJ: Mechanism and regulation of folate uptake by pancreatic acinar cells: Effect of chronic alcohol consumption. Am J Physiol Gastrointest Liver Physiol 298: G985-G993, 2010

129. Wani NA, Nada R, Khanduja KL and Kaur J: Decreased activity of folate transporters in lipid rafts resulted in reduced hepatic folate uptake in chronic alcoholism in rats. Genes Nutr 8: 209-219, 2013.

130. Mason JB and Choi SW: Effects of alcohol on folate metabolism: Implications for carcinogenesis. Alcohol 35: 235-241, 2005. 